\title{
Cerebellar Hypoperfusion in Migraine Attack: Incidence and Significance
}

\author{
(D)F. Kellner-Weldon, (D) M. El-Koussy, (D). Jung, (D) M. Jossen, DP.P. Klinger-Gratz, and (D) R. Wiest
}

\begin{abstract}
BACKGROUND AND PURPOSE: Patients diagnosed with migraine with aura have an increased lifetime risk of ischemic stroke. It is not yet clear whether prolonged cortical hypoperfusion during an aura increases the immediate risk of cerebellar infarction because it may induce crossed cerebellar diaschisis and subsequent tissue damage. To address this question, we retrospectively analyzed potential relationships between cortical oligemia and cerebellar hypoperfusion in patients with migraine with aura and their potential relation to small infarct-like cerebellar lesions.
\end{abstract}

MATERIALS AND METHODS: One hundred six migraineurs who underwent MR imaging, including DSC perfusion, were included in the study. In patients with apparent perfusion asymmetry, we used ROI analysis encompassing 18 infra- and supratentorial ROIs to account for differences in regional cerebral blood flow and volume. The presence of cerebellar hypoperfusion was calculated using an asymmetry index, with values of $>10 \%$ being considered significant.

RESULTS: We observed perfusion asymmetries in 23/106 patients, 22 in patients with migraine with aura (20.8\%). Cerebellar hypoperfusion was observed in 12/23 patients (52.2\%), and crossed cerebellar diaschisis, in 9/23 patients (39.1\%) with abnormal perfusion. In none of the 106 patients were DWI restrictions observed during migraine with aura.

CONCLUSIONS: Cerebellar hypoperfusion and crossed cerebellar diaschisis are common in patients with migraine with aura and cortical perfusion abnormalities. Crossed cerebellar diaschisis in migraine with aura may be considered a benign phenomenon because we observed no association with DWI restriction or manifest cerebellar infarctions, even in patients with prolonged symptom-related perfusion abnormalities persisting for up to 24 hours.

ABBREVIATIONS: $\mathrm{Al}=$ asymmetry index; $\mathrm{CCD}=$ crossed cerebellar diaschisis; $\mathrm{HCH}=$ hypoperfused cerebellar hemisphere; $\mathrm{MwA}=$ migraine with aura; $\mathrm{rCBF}=$ regional $\mathrm{CBF} ; \mathrm{rCBV}=$ regional $\mathrm{CBV}$

M igraine is the most frequent primary headache and affects up to $12 \%$ of the general population, ${ }^{1}$ causing disabling symptoms during attacks. Migraine without aura is defined as a recurrent headache with attacks lasting between 4 and 72 hours, typically unilateral, of pulsatile quality, with moderate severity that is aggravated by routine physical activity and associated with nausea and/or photo- and phonophobia. ${ }^{2}$ In contrast, migraine

Received June 28, 2016; accepted after revision November 5, 2017.

From the Support Center for Advanced Neuroimaging (F.K.-W., M.E.-K., M.J., P.P.K.-G., R.W.), Institute for Diagnostic and Interventional Neuroradiology, and Department of Neurology (S.J.), University Hospital Inselspital, Bern, Switzerland; and Department of Radiology (P.P.K.-G.), University of Basel, Basel, Switzerland.

This study was partially supported by Bayer (Swiss) AG, Zurich, Switzerland.

Please address correspondence to Frauke Kellner-Weldon, MD, Institute for Diagnostic and Interventional Neuroradiology, University Hospital Inselspital, 3010 Bern, Switzerland; e-mail: frauke.kellner-weldon@insel.ch

- Indicates open access to non-subscribers at www.ajnr.org

http://dx.doi.org/10.3174/ajnr.A5508 with aura (MwA) presents with transient focal neurologic symptoms that may mimic acute ischemic stroke, particularly if not immediately followed by a typical headache. ${ }^{1}$ Patients who have MwA have an increased lifetime risk of latent cerebellar infarctions that is twice as high as that in the unaffected population. ${ }^{3}$ In patients with MwA, most WM lesions (80\%) are observed in the posterior cerebral artery territory, most pronounced along vascular borderzones. Spreading oligemia associated with neuronal depression-a condition induced by a slowly propagating wave of neuronal and glial depolarization within the cerebral cortex- has been postulated as the most likely cause. ${ }^{4}$ Hemodynamic responses because of spreading depression may, like ictal and postictal neuronal activation and deactivation, induce regional brain perfusion changes that are sensitive to MR perfusion imaging. Variant patterns of perfusion changes have been observed during onset, spread, and termination of migraine attacks. ${ }^{5-8}$

Cortical hypoperfusion may also be associated with crossed cerebellar diaschisis (CCD), a depression of CBF and metabolism 


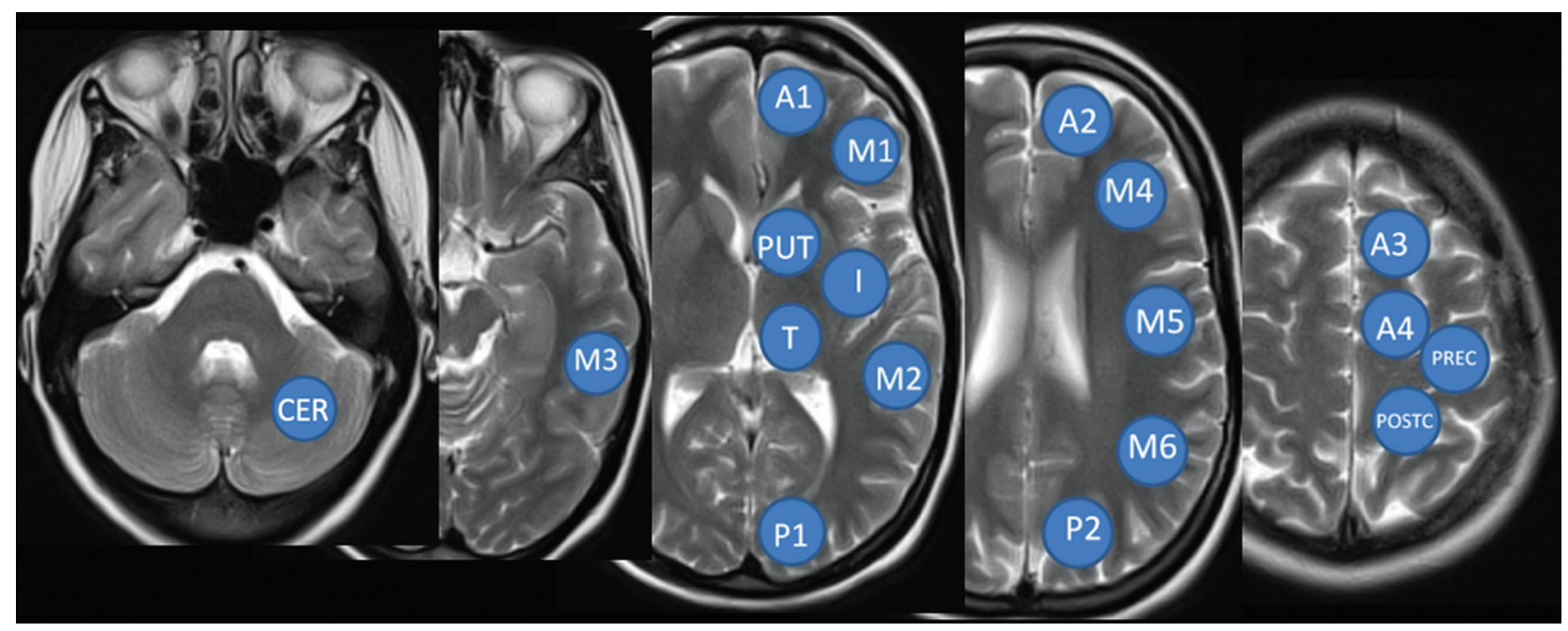

FIG 1. ROI analysis for perfusion parameters: CER indicates cerebellum; Put, putamen; I, insula; T, thalamus; A, arterial territory of the anterior cerebral artery; $\mathrm{M}$, arterial territory of the middle cerebral artery; P, arterial territory of the posterior cerebral artery; PREC, precentral gyrus; POSTC, postcentral gyrus.

in the cerebellar hemisphere contralateral to a supratentorial neuronal deactivation. CCD is observed in several disorders that result in neuronal damage or depletion, such as acute ischemic motor stroke, ${ }^{9,10}$ hemorrhage, ${ }^{11,12}$ and epilepsy with disturbance of the motor network. ${ }^{13}$ So far, CCD in migraine has only been described anecdotally ${ }^{14,15}$ as posing a risk of subsequent brain infarctions for patients with CCD. The aim of our study was to investigate the association between cortical oligemia and cerebellar hypoperfusion in patients with MwA and their potential relation to small infarct-like cerebellar lesions.

\section{MATERIALS AND METHODS \\ Study Population}

We retrospectively identified patients with a proved history of migraine, admitted to our tertiary care stroke center between October 2010 and October 2013 who were referred for MR imaging within 24 hours of onset of symptoms of suspected stroke. Patients were diagnosed with migraine if they fulfilled the criteria specified in the International Classification of Headache Disorders. ${ }^{2}$ The diagnosis was confirmed by a board-certified neurologist either at discharge or, in cases of a first episode, after confirmation during follow-up visits. The demographic characteristics and clinical history were obtained from the case records. The study was approved by the local ethics committee. Inclusion criteria were the following: 1) confirmed migraine according to the International Headache Society ${ }^{1}$; 2) MR imaging within 24 hours of the onset of symptoms according to the standardized stroke protocol, which included perfusion imaging. Exclusion criteria were any cause of secondary headache (eg, cerebral vascular ischemia, sinus venous thrombosis, tumor, hemorrhage, dissection, or encephalitis). Due to the retrospective nature of this study, we did not exclude patients who were taking medication.

\section{Image Acquisition}

The imaging studies were performed with either a $1.5 \mathrm{~T}$ or $3 \mathrm{~T}$ scanner (Magnetom Avanto, Magnetom Aera, or Magnetom Verio; Siemens, Erlangen, Germany) using a standard 12-channel head coil. Gadobutrol (Gadovist; Bayer Schering Pharma, Berlin, Germany) at $0.1 \mathrm{~mL} / \mathrm{kg}$ body weight was injected before the perfusion sequence. Perfusion parameters were as follows: 1.5T: TR, $1410 \mathrm{~ms}$; TE, $30 \mathrm{~ms}$; averages, 1; FOV read, $230 \mathrm{~mm}$; FOV phase, $100 \%$; voxel size, $1.8 \times 1.8 \times 5.0 \mathrm{~mm}$; flip angle, $90^{\circ}$; 80 repetitions; acquisition time, 1:59 minutes; 3T: TR, $1400 \mathrm{~ms}$; TE, $29 \mathrm{~ms}$; averages, 1; FOV read, $230 \mathrm{~mm}$; FOV phase, 100\%; voxel size, $1.8 \times 1.8 \times 5.0 \mathrm{~mm}$; flip angle, $90^{\circ}$; 80 repetitions; acquisition time, 1:59 minutes. Nineteen parallel images were acquired with a slice thickness of $5.0 \mathrm{~mm}$. Time-of-flight axial 3D MR angiography was performed with the following parameters for 1.5T: TR, 23 ms; TE, $7 \mathrm{~ms}$; flip angle, 25; FOV read, $230 \mathrm{~mm}$; FOV phase, 94\%; voxel size, $1.3 \times 1.2 \times 1.0 \mathrm{~mm}$; number of slices, 78 ; number of averages, 1; for 3T: TR, $22 \mathrm{~ms}$; TE, $3.6 \mathrm{~ms}$; flip angle, 18 ; FOV read, $181 \mathrm{~mm}$; FOV phase, $90 \%$; voxel size, $1.2 \times 1.2 \times 0.5 \mathrm{~mm}$; number of slices, 78; number of averages, 1 .

\section{Image Analysis}

Perfusion Analysis. Postprocessing for perfusion image analysis was performed with an FDA-approved postprocessing software package Olea Sphere 2.0 (Olea Medical, La Ciotat, France). The arterial input function was selected automatically using a cluster analysis algorithm, ${ }^{16}$ and the deconvoluted perfusion parameters were calculated using the oscillation index-type extension of the block-circulant singular value decomposition technique. ${ }^{17}$ Two radiologists with $>15$ years of experience qualitatively analyzed the perfusion data of all patients with the intention of depicting perfusion disturbances in any supratentorial area of the brain parenchyma on TTP, CBF, or CBV maps once consensus had been reached. The window width was manually adjusted to maximize visual contrast. The imaging data of patients with perfusion asymmetries were further analyzed in a semiquantitative fashion.

Semiquantitative Imaging Analysis. To account for focal changes of perfusion, ROI positioning followed the ASPECTS 


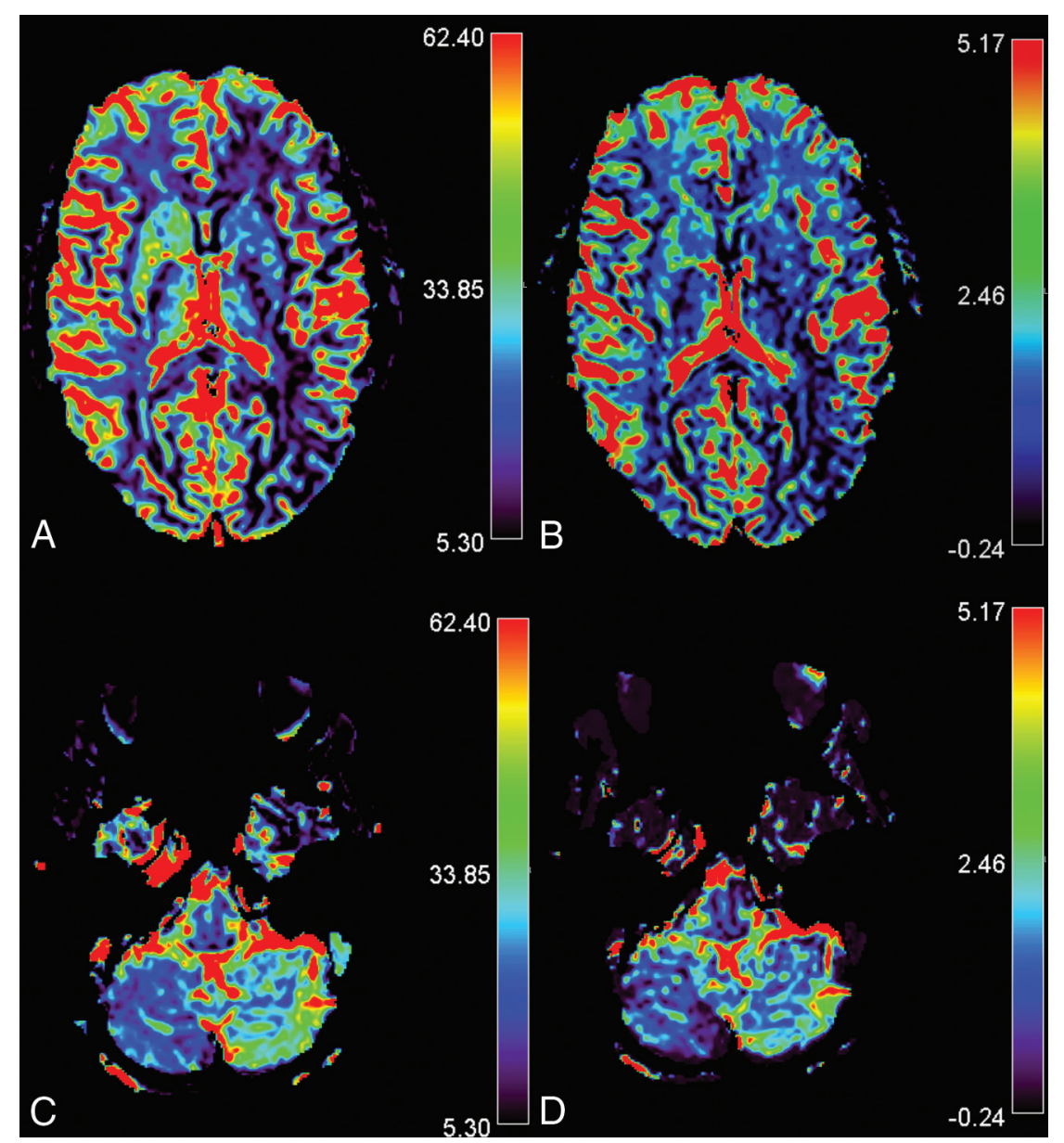

FIG 2. CCD in a 14-year-old girl presenting with MwA and CCD. Slices $A$ and $C$ show $r C B F$ images of the infra- and supratentorial brain, and slices $B$ and $D, r C B V$ images respectively. The patient presented with $\mathrm{HCH}$ in the right cerebellum with overt hemispheric perfusion asymmetry. Fourteen of 17 supratentorial ROIs in the left supratentorial hemisphere exceeded the Al threshold with lateralization of hypoperfusion contralateral to the cerebellum. Bars indicate relative values for $\mathrm{CBV}$ and CBF.

\section{Vertebral Artery Configuration}

The vertebral arteries were analyzed on TOF angiograms to look for patency or hypoplasia to exclude perfusion abnormalities in the PICA territory related to an occluded or hypoplastic vessel. Vertebral artery hypoplasia was defined as a diameter of the vertebral artery of $<1$ $\mathrm{mm}$.

\section{Statistics}

We used SPSS (Version 21; IBM, Armonk, New York) for statistical analysis. Descriptive data are presented as mean and SD or median. We used the Student $t$ test for normally distributed supratentorial data and the Mann-Whitney $U$ test for not normally distributed infratentorial data to compare numbers of ROIs with $\mathrm{AI}>10 \%$ and mean values of AI (\%) between groups. A $P$ value $<.05$ was considered significant.

\section{RESULTS}

We identified 191 patients with migraine from our data base. Of these, 106 patients underwent a dedicated stroke protocol within 24 hours of onset of symptoms and 98 were finally diagnosed with MwA. In 23/106 patients (21.69\%) patients, we identified focal cortical hypoperfusion. None of the patients presented with a DWI restriction. Fifteen of the 23 were female. Mean age was 28.8 years (range, 13-77 years). The laterality of the clinical symptoms was left-sided

score ${ }^{18,19}$ with 1 additional slice covering the sensory and motor cortex and frontal superior gyrus. ROIs were semiautomatically positioned on the postprocessed parameter maps, and the numeric values were extracted for TTP, MTT, regional CBF (rCBF), regional $\mathrm{CBV}$ (rCBV), and time-to-maximum of the tissue residue function time-to-maximum. ${ }^{16}$ For each hemisphere, 18 ROIs were placed as in Fig 1.

Because DSC MR perfusion imaging must be considered a semiquantitative method, we calculated an asymmetry index (AI) for the paired ROIs of the parameters rCBF and rCBV. ${ }^{20,21}$ The apparently more severely hypoperfused hemisphere was identified by experts. The AI was calculated using the following formula: $\mathrm{AI}=200 \times\left(\mathrm{ROI}_{\text {normal }}-\mathrm{ROI}_{\text {hypoperfused }}\right) /\left(\mathrm{ROI}_{\text {normal }}+\right.$ $\left.\mathrm{ROI}_{\text {contralateral }}\right){ }^{22}$ We heuristically set the cutoff at $>10 \%$ for asymmetric perfusion, in line with previous work on perfusion imaging in patients with epilepsy. ${ }^{23,24}$

CCD was defined as involving 2 conditions: 1) an AI value of $>10 \%$ within 1 hypoperfused cerebellar hemisphere $(\mathrm{HCH})$, and 2) an asymmetry in the contralateral hemisphere with an AI value of $>10 \%$ in a majority of any of the supratentorial ROIs.

A sample description is provided in Fig 2. in 8 patients and right-sided in 11. Alternating clinical patterns were observed in 2, and nonspecific symptoms, in 2 patients. MwA was the predominant final diagnosis in the patients with perfusion asymmetry, 22/23 patients.

For 13 of these 23 patients, the time between onset of symptoms and imaging was precisely documented (mean, 212 minutes; range, 95-429 minutes; median, 180 minutes). For the remaining 10 patients, the records documented MR imaging being performed within 12 hours of symptom onset. Of the 83 patients who had no perfusion alterations, the time between the onset of symptoms and MR imaging was precisely documented for 45 patients (mean, 384 minutes; range 55-1400 minutes; median, 315 minutes). For the remaining 38 patients, the onset of symptoms occurred up to 24 hours before the MR imaging. See Table 1 for clinical information on all patients and Table 2 for information on the subgroup of patients with and without CCD. Patients with cortical oligemia presented more often with aura symptoms than patients with normal perfusion. In patients with cortical oligemia, language and sensory symptoms were reported more frequently than visual and motor symptoms. Patients with $\mathrm{HCH}$ and the subgroup with CCD had a slightly lower frequency of 
sensory symptoms than the non-HCH group, but other aura symptoms were equally distributed between the groups (Tables 1 and 2). Aura symptoms were not a predictor of $\mathrm{HCH}$ or CCD (Table 2).

\section{Semiquantitative Evaluation}

Overall, we included 18 paired ROIs in the analysis. The size of each ROI was kept uniform for all patients but varied among regions to account for regional anatomy (mean, $291 \pm 100 \mathrm{~mm}^{2}$; range, $132-471 \mathrm{~mm}^{2}$ ). All 23 patients presented with at least 1 supratentorial ROI with an AI value of $>10 \% \mathrm{rCBF}$ and $\mathrm{rCBV}$.

Twelve patients had $\mathrm{HCH}$. Nine of these patients presented

Table 1: Clinical characteristics

\begin{tabular}{lccccc}
\hline & \multicolumn{2}{c}{$\begin{array}{c}\text { Abnormal } \\
\text { Perfusion }\end{array}$} & & \multicolumn{2}{c}{$\begin{array}{c}\text { Normal } \\
\text { Perfusion }\end{array}$} \\
\cline { 2 - 3 } \cline { 5 - 6 } Symptom & $\boldsymbol{n}=\mathbf{2 3}$ & $\%$ & & $\boldsymbol{n}=\mathbf{8 3}$ & $\%$ \\
\hline Headache & 21 & 91.3 & & 69 & 57.3 \\
Aura symptoms & 22 & 95.7 & & 76 & 63.1 \\
$\quad$ Visual & 10 & 43.5 & & 44 & 36.5 \\
Sensory & 17 & 73.9 & & 37 & 30.7 \\
Motor & 8 & 34.8 & & 22 & 18.3 \\
Language & 11 & 47.8 & & 16 & 13.3 \\
\hline
\end{tabular}

Table 2: Predominant clinical symptoms in patients with abnormal cortical perfusion

\begin{tabular}{|c|c|c|c|c|c|c|}
\hline \multirow{2}{*}{$\begin{array}{l}\text { Predominant } \\
\text { Symptom }\end{array}$} & \multicolumn{2}{|c|}{$\begin{array}{l}\text { Patients with } \\
\text { Oligemia }\end{array}$} & \multicolumn{2}{|c|}{ HCH (CCD Subgroup) } & \multicolumn{2}{|c|}{ Non-HCH } \\
\hline & $n=23$ & $\%$ & $n=12(9)$ & $\%$ & $n=11$ & $\%$ \\
\hline Headache & 21 & 91.3 & $10(7)$ & $43.5(30.4)$ & 11 & 47.8 \\
\hline Aura symptoms & 22 & 95.7 & $12(9)$ & $52.2(39.1)$ & 10 & 43.5 \\
\hline Visual & 10 & 43.5 & $5(2)$ & $21.7(8.7)$ & 5 & 21.7 \\
\hline Sensory & 17 & 73.9 & $7(5)$ & $30.4(21.7)$ & 10 & 43.5 \\
\hline Motor & 8 & 34.8 & $4(4)$ & $17.4(17.4)$ & 4 & 17.4 \\
\hline Language & 11 & 47.8 & $6(6)$ & $26.1(26.1)$ & 5 & 21.7 \\
\hline
\end{tabular}

Table 3: The number of ROls with an Al of $>10 \%$ in supratentorial oligemia (maximum, 17 per patient), in the group with hemispheric cerebellar hypoperfusion (154/204) and in the group with symmetric cerebellar perfusion (145/187)

\begin{tabular}{lcc}
\hline & \multicolumn{2}{c}{ Abnormal ROIs (AI > 10\%) } \\
\cline { 2 - 3 } & $\begin{array}{c}\text { Patients with Hemispheric } \\
\text { Cerebellar Hypoperfusion } \\
(\boldsymbol{n}=\mathbf{1 2})\end{array}$ & $\begin{array}{c}\text { Patients with Symmetric } \\
\text { Cerebellar Perfusion } \\
(\boldsymbol{n}=11)\end{array}$ \\
\hline rCBF (No.) & $154(75.5)$ & $145(77.5)$ \\
Total No. (\%) & 103 & \\
Contralateral & 51 & $139(74.3)$ \\
Ipsilateral & & \\
rCBV (No.) & $155(75.5)$ & \\
Total No. (\%) & 101 & \\
Contralateral & 54 & \\
Ipsilateral & & \\
\hline
\end{tabular}

Table 4: Mean Al for hypoperfused cerebellar hemisphere and non-HCH (rCBF and rCBV)

\begin{tabular}{|c|c|c|c|c|c|}
\hline & \multicolumn{4}{|c|}{ Al Absolute Values (\%) } & \multirow[b]{3}{*}{$P$ Value } \\
\hline & \multicolumn{2}{|c|}{$\begin{array}{c}\text { Group HCH } \\
(n=12)\end{array}$} & \multicolumn{2}{|c|}{$\begin{array}{c}\text { Group Non-HCH } \\
(n=11)\end{array}$} & \\
\hline & Mean & SD & Mean & SD & \\
\hline rCBF supratentorial & 27.60 & 6.85 & 26.30 & 6.66 & .51 \\
\hline rCBV supratentorial & 26.75 & 6.66 & 24.64 & 6.27 & .48 \\
\hline rCBF infratentorial & 30.56 & 16.77 & 4.24 & 3.23 & $<.001$ \\
\hline rCBV infratentorial & 25.69 & 16.00 & 4.02 & 2.53 & $<.001$ \\
\hline
\end{tabular}

a Significant differences were noted only for infratentorial ROls. with reduced $\mathrm{rCBF}$ contralateral to the ill-perfused cerebellar hemisphere (CCD-positive); in 3 patients, we detected cortical rCBF reduction ipsilateral to the cerebellum. All patients with $\mathrm{HCH}$ presented with clinical symptoms attributable to a region of cortical hypoperfusion in the contralateral hemisphere (Table 3).

When $\mathrm{HCH}$ was present, the number of ROIs with an $\mathrm{AI}>$ $10 \%$ found contralateral to the hypoperfused cerebellar hemisphere (103 for $\mathrm{rCBF}$ and 101 for $\mathrm{rCBV}$ ) was nearly twice the number of ROIs which exceeded the threshold of $10 \%$ in the psilateral hemisphere ( 51 for $\mathrm{rCBF}$ and 54 for $\mathrm{rCBV}$ ).

We observed no significant differences between $\mathrm{HCH}$ and non- $\mathrm{HCH}$ groups for mean $\mathrm{AI}$ values of $\mathrm{rCBF}$ and $\mathrm{rCBV}$ in the

\section{Vertebral Artery Configuration}

patients, the vertebral artery appeared normal. One papered into the PICA on the side of the hypoperfused

\section{DISCUSSION}

In this retrospective single-center study, we aimed to investigate the association between oligemia and $\mathrm{HCH}$ in patients with migraine and its potential relation to small infarct-like cerebellar lesions. We observed cortical oligemia in 23/ $106(21.69 \%)$ patients who underwent MR imaging to rule out ischemic stroke. Fifty-two percent of patients with oligemia presented with abnormal cerebellar perfusion, and 39.1\% fulfilled the criteria for CCD, rendering it a frequent consequence of cortical spreading depression unrelated to vertebral artery hypoplasia. ${ }^{25}$

Cerebellar hypoperfusion in patients with stroke is associated with a worse clinical outcome than if it was not present, related to deafferentation and transneural metabolic depression. ${ }^{26}$ In seizure-related CCD, the outcome is variable, ranging from complete neurologic recovery to permanent disability depending on the duration of prolonged excitatory synaptic activity affecting cortico-ponto-cerebellar pathways. ${ }^{27-31}$ While diffusion restriction is a common consequence of perfusion changes and related metabolic depletion in patients with stroke and epilepsy, this should be considered an exceptional phenomenon in migraine. In our cohort, none of the 106 patients had restricted diffusion or preexisting cerebellar infarct-like lesions. Although CCD was frequent, none of our patients with migraine experienced permanent deficits. We conclude that unlike in stroke- and seizure- 
related $\mathrm{CCD}, \mathrm{CCD}$ in MwA may be considered a benign phenomenon.

Cerebellar hypoperfusion has been addressed as a potential cause of cerebellar infarct-like lesions in MwA in previous studies. ${ }^{3}$ The findings of our retrospective study do not support the hypothesis of an increased risk of episode-triggered and oligemiarelated hypoxic cerebellar infarctions. In our series, none of the patients with oligemia reached the ischemic threshold. In patients with MwA, the severity of cortical oligemia, expressed as increasing $\mathrm{AI}$, was not directly associated with $\mathrm{HCH}$ or $\mathrm{CCD}$, in contrast to observations in patients with ischemic stroke. ${ }^{30}$ The size of the supratentorial oligemic area, expressed by the number of supratentorial ROIs beyond the threshold AI of $>10 \%$, also did not predict the likelihood of $\mathrm{HCH}$ or CCD. From a methodologic point of view, we excluded the transition parameters (TTP and MTT) from our perfusion analysis. Our findings were in line with those of Förster et al, ${ }^{32}$ who demonstrated that perfusion abnormalities in patients with MwA are predominantly substantiated by CBF and CBV changes. TTP analysis of the cerebellar hemispheres is hampered by variant vertebral artery configurations that directly influence the TTP and MTT maps, while no such detrimental effects have been reported for CBF analysis. ${ }^{24}$

Furthermore, it is not yet known whether the development of infarct-like lesions is facilitated by multifactorial interactions of severe oligemia with other impeding factors that are not detected by perfusion MR imaging (eg, increased vulnerability to blood flow reduction). An increased susceptibility to acute ischemic injury has been demonstrated in patients with migraine, due to an unstable penumbra, especially in those with MwA. ${ }^{33}$ Greater susceptibility to spreading depolarization in migraine-susceptible brains may be another potential mechanism for increased cerebral vulnerability to ischemia and stroke. Similar findings have been reported in an animal study. ${ }^{34}$ Thus, typical episodes with regularly experienced aura symptoms may reflect benign oligemia not related to tissue damage, while prolonged and severe hypoxic episodes may ultimately induce parenchymal damage, which was not observed in our cohort.

This study has some limitations. Due to its retrospective design, there was no healthy control group. Because expert analysis was performed to select apparent perfusion deficits in patients with migraine, a rater-dependent bias cannot be fully excluded. However, in healthy volunteers, interhemispheric asymmetry is minimal (1.01\%-3.14\%) and symmetric rCBF distribution can be assumed between homologous regions, independent of age. ${ }^{35}$ Thus, our ROI-based semiquantitative analysis with the rather strict threshold of $>10 \%$, as commonly used in stroke or epilepsy studies, may be considered appropriate to balance measurements of random asymmetry and spreading oligemia. ${ }^{22-24}$ Finally, all patients were symptom-free during follow-up. However, we cannot fully exclude the possibility that asymptomatic parenchymal damage may have remained undetected. Further studies would be required to answer this question.

\section{CONCLUSIONS}

$\mathrm{HCH}$ and CCD are frequently observed in patients presenting with acute MwA. Cerebellar hypoperfusion in patients with migraine appears, in contrast to stroke- and seizure-related CCD, to be a benign phenomenon. Our study could not provide evidence for a link between cerebellar hypoperfusion and cortical hypoperfusion in the pathogenesis of cerebellar infarctions but encourages future investigations that pay special attention to factors other than hypoperfusion alone to better understand the cause of infarct-like lesions in the cerebellum of patients who have MwA.

Disclosures: Roland Wiest-UNRELATED: Grants/Grants Pending: Swiss National Foundation, Swiss Heart Foundation.

\section{REFERENCES}

1. Lipton RB, Stewart WF, Diamond S, et al. Prevalence and burden of migraine in the United States: data from the American Migraine Study II. Headache 2001;41:646-57 CrossRef Medline

2. Headache Classification Subcommittee of the International Headache Society. The International Classification of Headache Disorders: 2nd ed. Cephalalgia 2004;24(Suppl 1):9-160 CrossRef Medline

3. Kruit MC, van Buchem MA, Hofman PA, et al. Migraine as a risk factor for subclinical brain lesions. JAMA 2004;291:427-34 CrossRef Medline

4. Kruit MC, Launer LJ, Ferrari MD, et al. Infarcts in the posterior circulation territory in migraine: the population-based MRI CAMERA study. Brain 2005;128(Pt 9):2068-77 CrossRef Medline

5. Olesen J, Larsen B, Lauritzen M. Focal hyperemia followed by spreading oligemia and impaired activation of rCBF in classic migraine. Ann Neurol 1981;9:344-52 CrossRef Medline

6. Kapinos G, Fischbein NJ, Zaharchuk G, et al. Migraine-like headache with visual deficit and perfusion abnormality on MRI. Neurology 2010;25;74:1743-45 CrossRef Medline

7. Fernandes PM, Whiteley WN, Hart SR, et al. Strokes: mimics and chameleons. Pract Neurol 2013:21-28 CrossRef Medline

8. Magauran BG Jr, Nitka M. Stroke mimics. Emerg Med Clin North Am 2012;30:795-804 CrossRef Medline

9. Yamauchi H, Fukuyama H, Nagahama Y, et al. Uncoupling of oxygen and glucose metabolism in persistent crossed cerebellar diaschisis. Stroke 1999;30:1424-28 CrossRef Medline

10. Yamauchi H, Fukuyama H, Kimura J, Hemodynamic and metabolic changes in crossed cerebellar hypoperfusion. Stroke 1992; 23:855-60 CrossRef Medline

11. Noguchi T, Nishihara M, Egashira Y, et al. Arterial spin-labeling MR imaging of cerebral hemorrhages. Neuroradiology 2015;57:1135-44 CrossRef Medline

12. Fu J, Chen WJ, Wu GY, et al. Whole-brain 320-detector row dynamic volume CT perfusion detected crossed cerebellar diaschisis after spontaneous intracerebral hemorrhage. Neuroradiology 2015; 57:179-87 CrossRef Medline

13. Nakae S, Inamasu J, Ohmi T, et al. Relative vasodilatory change in seizure-induced crossed cerebellar diaschisis. Intern Med 2016;55: 713-14 CrossRef Medline

14. Dodick DW, Roarke MC. Crossed cerebellar diaschisis during migraine with prolonged aura: a possible mechanism for cerebellar infarctions. Cephalalgia 2008;28:83-86 CrossRef Medline

15. Crawford JS, Konkol RJ. Familial hemiplegic migraine with crossed cerebellar diaschisis and unilateral meningeal enhancement. Headache 1997;37:590-93 CrossRef Medline

16. Mouridsen K, Christensen S, Gyldensted L, et al. Automatic selection of arterial input function using cluster analysis. Magn Reson Med 2006;55:524-31 CrossRef Medline

17. Wu O, Østergaard L, Weisskoff RM, et al. Tracer arrival timinginsensitive technique for estimating flow in MR perfusionweighted imaging using singular value decomposition with a block-circulant deconvolution matrix. Magn Reson Med 2003;50: 164-74 CrossRef Medline

18. Aviv RI, Mandelcorn J, Chakraborty S, et al. Alberta Stroke Program Early CT Scoring of CT perfusion in early stroke visualization and 
assessment. AJNR Am J Neuroradiol 2007;28:1975-80 CrossRef Medline

19. Puetz V, Khomenko A, Hill MD, et al. Basilar Artery International Cooperation Study (BASICS) Group: extent of hypoattenuation on CT angiography source images in basilar artery occlusion-prognostic value in the Basilar Artery International Cooperation Study. Stroke 2011;42:3454-59 CrossRef Medline

20. Strother MK, Buckingham C, Faraco CC, et al. Crossed cerebellar diaschisis after stroke identified noninvasively with cerebral blood flow-weighted arterial spin labeling MRI. Eur J Radiol 2016;85: 136-42 CrossRef Medline

21. Madai VI, Altaner A, Stengl KL, et al. Crossed cerebellar diaschisis after stroke: can perfusion-weighted MRI show functional inactivation? J Cereb Blood Flow Metab 2011;31:1493-500 CrossRef Medline

22. Takano A, Shiga T, Kobayashi J, et al. Thalamic asymmetry on interictal SPECT in patients with frontal lobe epilepsy. Nucl Med Commun 2001;22:319-24 CrossRef Medline

23. Wiest R, von Bredow F, Schindler K, et al. Detection of regional blood perfusion changes in epileptic seizures with dynamic brain perfusion CT: a pilot study. Epilepsy Res 2006;72:102-10 CrossRef Medline

24. Hauf M, Slotboom J, Nirkko A, et al. Cortical regional hyperperfusion in nonconvulsive status epilepticus measured by dynamic brain perfusion CT. AJNR Am J Neuroradiol 2009;30:693-98 CrossRef Medline

25. Thierfelder KM, Baumann AB, Sommer WH, et al. Vertebral artery hypoplasia: frequency and effect on cerebellar blood flow characteristics. Stroke 2014;45:1363-68 CrossRef Medline

26. Takasawa M, Watanabe M, Yamamoto S, et al. Prognostic value of subacute crossed cerebellar diaschisis: single-photon emission CT study in patients with middle cerebral artery territory infarct. $A J N R$ Am J Neuroradiol 2002;23:189-93 Medline

27. Graffeo CS, Snyder KA, Nasr DM, et al. Prognostic and mechanistic factors characterizing seizure-associated crossed cerebellar diaschisis. Neurocrit Care 2016;24:258 - 63 CrossRef Medline

28. Kato T, Okumura A, Hayakawa F, et al. Transient reduced diffusion in the cortex in a child with prolonged febrile seizures. Brain Dev 2012;34:773-75 CrossRef Medline

29. Massaro AM. Teaching neuroimages: crossed cerebellar diaschisis in hemispheric status epilepticus. Neurology 2012;79:e182 CrossRef Medline

30. Zaidi SA, Haq MA, Bindman D, et al. Crossed cerebellar diaschisis: a radiological finding in status epilepticus not to miss. BMJ Case Rep 2013;2013. pii: bcr2013200478 CrossRef Medline

31. Ohe Y, Hayashi T, Deguchi I, et al. A case of nonconvulsive status epilepticus with a reversible contralateral cerebellar lesion: temporal changes in magnetic resonance imaging and single-photon emission computed tomography finding. J Stroke Cerebrovasc Dis 2013;22:e639-42 CrossRef Medline

32. Förster A, Wenz H, Kerl HU, et al. Perfusion patterns in migraine with aura. Cephalalgia 2014;34:870-76 CrossRef Medline

33. Mawet J, Eikermann-Haerter K, Park KY, et al. Sensitivity to acute cerebral ischemic injury in migraineurs: a retrospective case-control study. Neurology 2015;85:1945-49 CrossRef Medline

34. Eikermann-Haerter K, Lee JH, Yalcin N, et al. Migraine prophylaxis, ischemic depolarizations, and stroke outcomes in mice. Stroke 2015; 46:229-36 CrossRef Medline

35. Catafau AM, Lomeña FJ, Pavia J, et al. Regional cerebral blood flow pattern in normal young and aged volunteers: a $99 \mathrm{mTc}-\mathrm{HMPAO}$ SPET study. Eur J Nucl Med 1996;23:1329-37 CrossRef Medline 